\title{
START TO CHANGE THE START - THE TARGET SYSTEMIC MODEL
}

\author{
Author(s) / Auteur(s) : \\ Daniela TERRILE \\ PoliDesign - Politecnico di Milano, Milan (Italy) \\ systemic4all ${ }^{\circledR}$ methodology on practising \\ daniela.terrile@gmail.com
}

\begin{abstract}
Résumé :
Strategic Design is 'designed' 'to produce' Product Service Systems. Students from 15 countries and speaking 14 different languages were attending a Master in Strategic Design which was opened for training professionals in the integration of product, service and communication components.
\end{abstract}

Keywords / Mots-clés :

technology of systemic constellation, technology of consciousness, systemic coaching, from ego to eco learning, transformational learning, target systemic constellation

\section{INTRODUCTION}

This new model is the result of a research at PoliDesign (POLITECNICO DI MILANO) on strategic design approach, during the Master Strategic Design, with participants of different countries, following the study on Objective's Structural Constellation of Insa Sparrer and Mathias Varga.

The Morphic field of the Constellations is unfolding similar approaches, as this study seems to be, and after 5 years of research at Polidesign, I finally created this new model "target systemic constellation" (or target systemic model).

\section{WHAT IT IS}

Target Systemic Constellation is a physical experience: every "quest" is the fundamental to unfold a solution, which is necessary to evolve in a pre-fixed system. People are experiencing "the solution" as determined by their target question.

This methodology leads to experience the perspectives of other people (groups of people), therefore it is inclusive, integrated and permanently evolving.

It illustrates a broader picture of the "quest" by using emotions we enter into a dialogue with them, through the exploration of three different targets (space, time, relationship):

\section{1. belonging \\ 2. order \\ 3. balance}

Normally we speak of the relationship between the 3 spatial directions (length, width, height) and time as it passes. We use the relationship of space and time in conjunction with Einstein's Theories of Relativity. Essentially, we are trying to model the universe mathematically and hoping to observe it by looking through telescopes and using other sensors.

Think of a simple example as of you in a room and you simply dance around for 30 minutes. The relationship is then tracking your movements over the 30 min of time, then seeing if we can predict anything about your behavior(as the object).

However, what if, we could take the relationship, as an element per sé, and not strictly linked to space and time? So to say, we would have three different elements, which have a distinctive existence. 
There are tons of very theoretical math available, but it very difficult to follow w/o the background to start with. For those of us who have studied the subjects of theoretical mathematics, physics and astrophysics, and cosmology (studying the cosmos and its history) it can be extremely interesting

Finally, by changing perspectives according to the different questions, the constellation model has the following three advantages:

a) Adding and changing the target categories is easy. In this research field, recognitions methods are often categorized as:

- a generative cause - effect model: inclusive

a discriminative model: selective

The target model is a generative model, which individually makes a model for each target category. This model is personal and unique for the client, and it is very useful to identify which resources he needs to move forward, to overcome his difficulties and to find the right balance to approach reality.

In the target constellation model the multi-target approach can be experienced in one's own body (and in the body of the representatives). The method of the target systemic constellation offers a change in the perspectives of the client and enhances their own esteem. By seeing the hidden dimensions, and be confronted to the 'target' it is much easier to see what they normally do not want or cannot see.

Thus an understanding is automatically generated, therefore in the awareness process for changing the already learnt target categories, it is only necessary to change the way we see the problem: no other process is needed.

This method helps to ignite solutions and to discover the first steps to move forward. On the other hand, there are no discriminations, no mistakes, no boundaries, and no judgements. The main goal is to enhance phenomenology to unfold new challenges. During the target constellation, the client has the chance to re-set the frame of his quest, to eliminate what is redundant, no functional, and at each time reframe, add, change, adapt according to what the system unfolds as possible solutions.

It is a learning process; no one can intervene as teacher, master, expert, and consultant. We are not looking for solutions we know already we just trust the field. The system knows always what is better for the client.

b) Description accuracy is higher due to a continuous value expression. The sum is more and something completely different from the single target solutions. The target model is a continuous value expression by probability function, and by testing on the client body, the effects are immediate.

c) Position and scale information can be used effectively. The client can experience multiple target solutions, and decide which one is preferable in that specific moment. Client can ignore spatial information to avoid complicated spatial relationships with his system, or alternatively, he can decide to open the field, let it go, and measure the satisfaction of his body, by orienting towards the target solution, which fits the most.

The target constellation model is extendable to a multimodal constellation. A unimodal model has to represent several types of appearances as one target solution. Nevertheless, by extension to a multimodal model some appearances can be transformed and unfold as the most appropriate to transform the challenge into a result.

Moreover, when using the target constellation model, the idea is to empower the client, to go beyond his boundaries and to accept the proposed "set" as a concept that may be helpful to keep the essential and transform what is useless, and out of fashion.

In a target constellation, is the body that understands and let the information emerge. The client can trust the feeling that at unconscious level he has all information and resources they need.

The brain normally blocks the flow, and stops the process by not accepting, cancelling, distorting or generalizing what the body is experiencing.

One of the reasons the target constellation model can be attractive for individual, organizations, and academia is the fact that it can serve aspects and purpose of management as well as the success of an organization and its staff. Some of these questions can be explored. 
- What can safeguard the success and the sustainability of an academia?

- How can strengths, resources and competencies, be found and optimized throughout it?

- What can be done to design a transformation in an individual or academia more efficiently?

- How can, in times of dwindling resources, challenges for student be transformed efficiently?

- And last but not least: How can solutions be explored with innovation?

\section{CASE STUDY: MASTER STRATEGIC DESIGN}

Strategic Design is a design activity that concerns Product Service System, i.e. the integrated body of products, services and communication strategies that either an actor or a network of actors (companies, institutions, non-profit organizations, etc.) generate and develop to co-create value. It is often claimed that technological innovation, cultural and economic globalization, and the transition to environmental sustainability generate problems and opportunities. It is also repeatedly stated that the possibility to avoid the former and to exploit the latter requires the development of three core skills: visioning, sensing innovation, creating solutions embedded in new business models.

It calls for the ability to design products and services whose success today anticipates what will be, or may have to be, the norm of tomorrow. The social demand for a new generation of products and services, coherent with current socio-cultural transformations, and their sustainable development becomes an opportunity for companies able to operate in the context of this new design mind-set: strategic design.

\section{OBJECTIVES OF THE MASTER}

The educational objective of the Master is to build a specific competence and qualified professionalism in strategic design issues and in the innovation and design of the product system.

Its particular purpose is to train professionals in the integration of product, service and communication components.

Target systemic constellation therefore, is extremely crucial in defining what kind of communication students want to adopt, in guiding their future clients, demonstrating how to build rapport, to understand their needs, and help them to develop appropriate strategies to find solutions and innovative products.

The University is challenging to do so by developing specialized skills directed towards enhancing those qualities (real and perceived) of the overall process that will determine the cultural identity, the sensory aspects and the sustainability of the designed solutions. Students learn how to co-create and collaborate in a multicultural environment: this year 25 students represented 15 different countries and speaking 14 languages.

The Master program offers an "on field" training experience, where research and innovation focus on real cases and contexts. It is orientated towards a high degree of professional competence, since it aims to provide conceptual and practical tools applicable in the social and economic reality of the world today. The Master program seeks to:

- develop strategic planning skills in terms of problem-setting and problem-solving;

- develop personal entrepreneurship aptitude;

- develop complexity management skills;

- develop competencies to generate corporate visions;

- acquire management skills for strategic design projects;

- acquire the necessary tools to communicate strategic design projects. 


\section{PURPOSE OF MY INTERVENTION AT THE MASTER}

When Politecnico di Milano asked me if I wanted to join the academy, it was clear to me the mission and purposes of the module "empowerment": the opportunity for students and future strategic designers, to map the world, utilizing a target systemic model.

This empowered embodied self-observation is the key for those students who are willing to understand their strengths, values, interests, purpose and passion, being responsible for their own actions and decisions, working on their limiting beliefs, accepting feedback and willing to change perspective and test those challenges which stretch their comfort zone to learn and unfold hidden dimensions.

\section{THE LEARNING CURVE, PROCESS AND OUTCOME}

My course uses target systemic model to address the "wicked problem" for participants when they design their life and career. My class offers a framework, tools, and most importantly a place and a community where to work on these issues through assigned readings, reflections, and in-class exercises. The course employs a designing thinking approach to support students from any major navigate the challenges of their life. No teachers, no professors, only peer-to-peer approach; that is the academic innovation.

For students dealing with issues ranging from how to find and experience sense making in work, this model is an opportunity to strengthen:

- Attitude - for succeeding in university and designing the action plan of the projects at 1, 3 and 5 years, finding a meaningful and sustainable motivation

- Motivation - Students have a greater degree of accepting responsibility for the tasks necessary for academic success and to feed their exploration for their future professional commitment

- Intention - an intention to maintain their heart and head open to see those hidden dimensions that can be useful to transform their life and to learn how to assist their future clients.

My proposal is therefore a genuine alternative to what constitutes most Master programmes. Target systemic model is building a unique relationship between the student and his potential, and between the student and the contents of the Master class: students feel at ease when they can experience under no judgement, no performance, and no boundaries, trusting their own body functioning as a resonance box.

They decide what boundaries they want to define, and over rule. Under these circumstances, the quality of listening is the first step to move forward and adapt accordingly.

Is target systemic model, a model to evolve the "system" in which we operate? Humans have gained so much knowledge about the world and cause-effect relations but are not able or willing to transfer it into practice and action accordingly and comprehensively (Marlen Gabriele Arnold, 2017). 


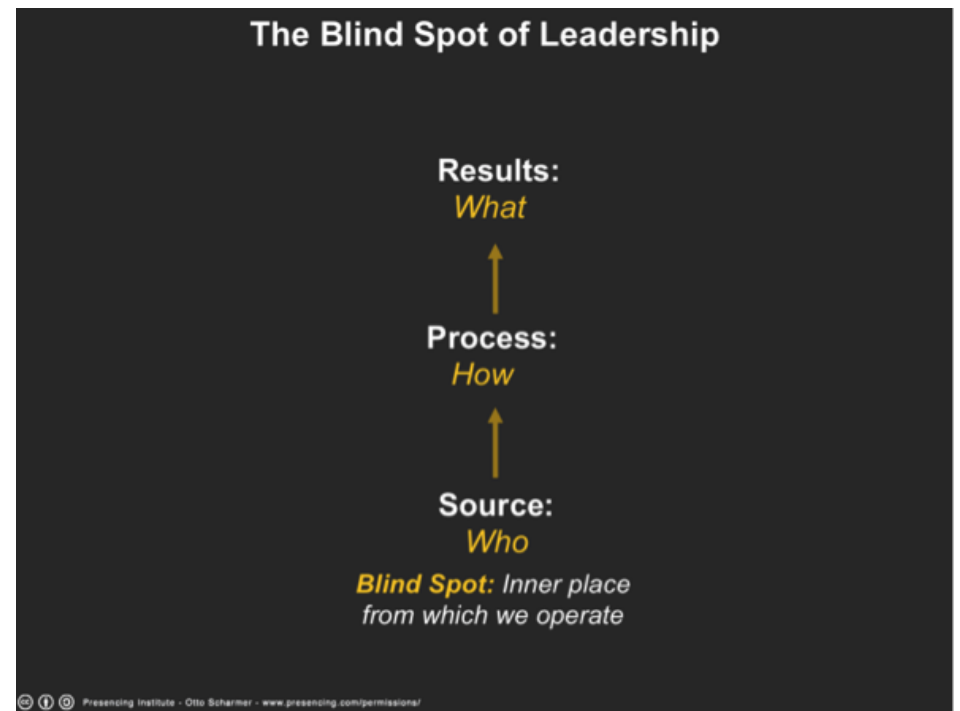

\section{EMPOWERING FROM THE EMERGING FUTURE}

In exploring this territory more deeply, Otto Scharmer he realized that most of the existing learning methodologies relied on learning from the past, while most of the challenges in organizations seemed to require something quite different: letting go of the past in order to connect with and learn from emerging future possibilities.

\section{What if}

Can we trust and develop a methodology in this new type of learning, so to say "learning from the emerging future"?

Can an intimate relationship with a deeper source of knowing, a different quality of presence, serve the purpose?

Presencing is a blended word combining "sensing" (feeling the future possibility) and "presence" (the state of being in the present moment): presencing means "sensing and actualizing one's highest future possibility - acting from the presence of what wants to emerge."

My experience with students of Master Strategic Design is that the so-called first level "downloading" describes habitual behaviour: consequently, thoughts and results are in "the same old" outcome: this type of listening originates from the centre of our habits, from what we already know from past experience.

In contrast, level four listening, called presencing (Otto Scharmer_ Theory U), represents a state of the social field in which the circle of attention widens and a new reality enters the horizon and comes into being.

In this state, listening originates outside the world of our preconceived notions. We feel as if we are connected to and operating from a widening surrounding sphere. As the presence of this heightened state of attention deepens, time seems to slow down, space seems to open up, and the experience of the self-morph from a single point (ego) to a heightened presence and stronger connection to the surrounding sphere (eco).

What does it take for individuals, teams, institutions, academia and larger systems to perform the same sort of shift from downloading to presencing? 


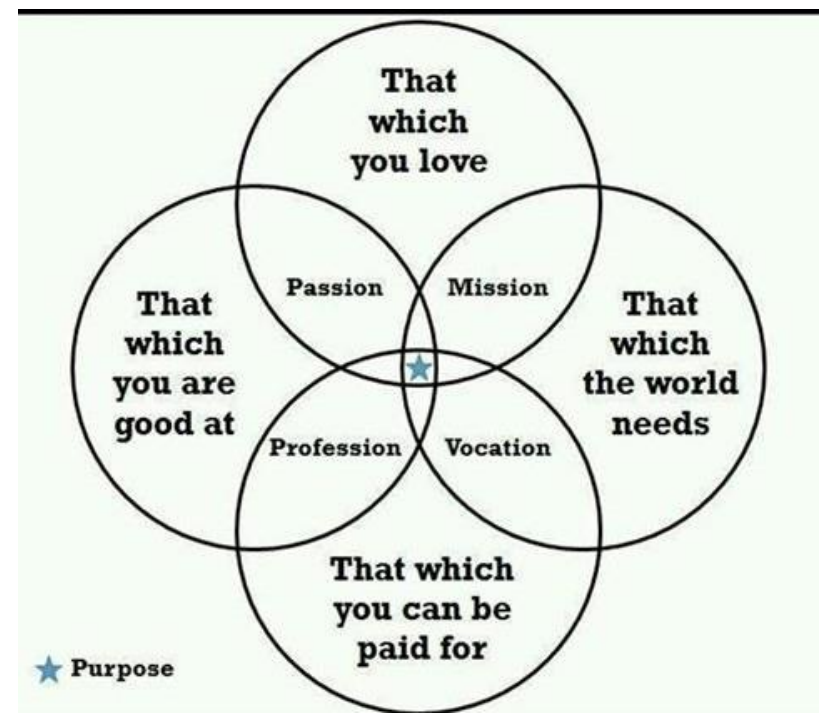

While working with students the listening from the field attitude makes the difference when "presencing" is transforming the ego-process into eco-process: students are looking for innovative ideas, products and strategies, which involve less environmental impacts throughout life cycle.

When the target systemic model activity integrates the following principles, students can develop new insights and enhance their capacities at designing:

- multi-stages: all the stages of the product life cycle; including what the world needs and what we can be paid for.

- multi-components: systemic; including what they are good at and what they love.

- multi-fractional: all the different target, are a small part of the system and evidence the hidden dimensions that can help to have a broader view. View is vision on the future.

For the purpose of this research, I have asked some questions so far:

- "What are you doing differently that you may otherwise not have done without the target systemic model?"

- "What have you learned, in this Master, that you could utilize in another field of your professional and personal life?

- "What have you learned about yourself and your personal and professional skills?

Responses to these questions, showed that this model is reinforcing their personal strengths, give new insights, support in building a more structural mind-set, help in preparing for an interview, support in focusing on what is important. Target systemic model is an innovative tool to understand how to move forward, empower students to make clear statement, and build their understanding of a specific situation, on a greater awareness of their potential for change.

Target systemic model construct a solid theory out of building block, a theory that can stand without the use of metaphors and comparisons (Systemic Consultancy in Organizations, 2005, R. Konigswieser - M. Hillebrand). 


\section{B O B (BALANCE, ORDER, BELONGING)}

- Difference (deviation, richness, distinction, environment / system) - Balance

- Order (patterns, rules, structures) - disorder (chaos, entropy)

- Transition (development, change, history, genesis) from chaos to order to chaos

- Permanence (durability, unchangeableness - changeability (change, dynamics, evolution)

- Delimitation (unity, internal, self-referencing) - communication (openness, exchange, external, environment)

- Information (formation, establishment or order) - deformation (destruction, elimination, downfall)

- Complexity (multiple layers, relationships, meanings) - Belonging (unity, identity)

In this structure, it is hard to find something 'tangible' for scientific purpose; nevertheless, the rules to define a system are belonging, order and balance.

For students, in order to be able to analyze their professional life, and further, think strategically when they approach their future clients, these simple rules can show immediately if the system is in good health, if the applied strategy support order, if all people belonging to the system have their place, and if the system is well balanced.

\section{CRITICAL SUCCESS FACTORS THAT CONTRIBUTED TO GOAL ACHIEVEMENT}

In analyzing the results of both target systemic model in groups and bilateral sessions, I could support participants to take immediate action to move forward and regain control of their future professional life, with a broader choice of actions and the challenge to enlarge the spectrum of their map of the world.

When facing problems, students could explore alternatives that the traditional conceptual images of classical physics (made up of rigid, fixed elements = object plus cause/force/action leads to effect/motion/reaction) could not be used to describe states of order and disorders. This new scientific language could unfold different conceptual images and paradigms, a new theory.

I asked participants to identify the critical success factors that made this experience particularly effective:

- the assessment of the situation,

- the exploration in meta position (target emotions),

- the exploration from a systemic point of view (society, world, nature, family),

- a much clear vision of their map of the world

- the support in building their "map"

- the challenge of thinking that the constraints and changes can show the necessity of moving and changing an attitude or a limiting beliefs.

\section{TARGET SYSTEMIC MODEL AS A HUMAN CAPITAL MANAGEMENT}

I consider the benefit of this model, for the entire Organization (the Academia as a whole), directly linked to "Human Capital" management. This model is intrinsically linked to emotions, and everything linked with emotions is scaring and sometimes uncomfortable.

\section{How to achieve benefit through "people" rather than through performance?}

When dealing with people, I sense the importance of "being human". 
I listened to an inspiring interview of Marshall Goldsmith where he said: "As a coach, you should realize that success with your clients is not about you. It is about the people who choose to work with you".

In a way, I feel the same. The success of people, is not about me. It is all about the great people who are working with me.

"The best mentor/coach/consultant, the people do not notice. When the best coach's work is done, the people say, "We did it ourselves.'"

Whether we like it or love it, the term 'human capital' is here to stay and is now accepted as a common definition of all the important people element of intangible value. Intangible value is constantly increasing when listening to students, generally speaking, to people and providing the information to teachers, management, top hierarchy, that will help them understand just what it is that their students are willing to create, innovate and contribute.

\section{CONCLUSION}

In their discussion of 'good' learning which draws on research from all sectors of education, Collins, Harkin and Nind (2002, p.11) highlight that in order to foster effective learning, "it should be transformative, active, interactive, intrinsically motivating and lifelong". It is interesting to note, that these factors are strongly reflected in target systemic constellation processes and outcomes as evidenced within empirical studies, technical literature and within the above discussion of learning theory employed within coaching practice.

As coaching, target systemic model in Academia is still in its fetal stage. Despite this, by drawing upon the limited body of evidence-based systemic model knowledge from various contexts, I tried to evidence how strategic design and new learning indeed appear to be at the heart of this model.

Underpinning the goal-directed, action-based framework of coaching which combines powerful dialogue within a supportive yet challenging arena, are the concepts and approaches encouraged within adult and lifelong learning, transformational learning, experiential learning and mentoring theory. Through a synthesis of learning theory contained within a holistic model that provides a practical bridge between many previously mutually exclusive disciplines and schools of thought an effective approach to teaching and learning is therefore proposed.

\section{RÉFÉRENCES}

Costa, A.L. (1992). An environment for thinking. In Collins, C., \& Mangieri, J.N. (Eds.), Teaching Thinking: An agenda for the $21^{\text {st }}$ century (pp. 169-181). New Jersey: Lawrence Erlbaum Associates Publishers.

Costa, A.L. (2000). Mediative environments: Creating conditions for intellectual growth. In Kozalin, A., \& Rand, Y. (Eds.), Experience of mediated learning: An impact of Feuersteins's theory in education and psychology (pp.34-44). Amsterdam: Elsevier Science.

Costa, A.L. \& Garmston, R.J. (1994). Cognitive coaching: A foundation for renaissance schools. Massachusetts: Christopher-Gordon Publishers Inc.

Creane, V.E. (2002). An exploratory study of personal coaching from the client's perspective. Unpublished doctoral dissertation, California Institute of Integral Studies, San Francisco, USA.

Daloz, L.A. (1986). Effective teaching and mentoring: Realizing the transformational power of adult learning experiences. San Francisco, Jossey-Bass Publishers.

Dansinger, S. (2000). Academic coaching for the gifted learning. 6/28/00 (ERIC Document Reproduction Service No. ED444278)

Duff, P.J.J. (2002). The Role of personal coaching in enhancing leadership confidence and learning capability. Unpublished masters dissertation, Royal Roads University.

Evered, R.D. and Selman, J.C. (1989). Coaching and the Art of Management. American Management Association in Organizational Dynamics. Coaching Connection. [Online]. Available at: http://coaching.gc.ca/documents/coaching_and_the_art_of_management_e.asp\#2 [ $20^{\text {th }}$ October 2004]. 
Freire, P. (1990). Pedagogy of Freedom: Ethics, Democracy and Civic Courage. New York: Rowan and Littlefield Publishers, Inc.

Gale, J., Liljenstrand,A., Pardieu, J., \& Nebeker, D.M. (2002). Coaching : Who, What, Where, When and How. California School of Organizational Studies at Alliat International University. [Online]. Available at: http://www.coachfederation.org/pressroom/news.asp [15 ${ }^{\text {th }}$ October 2003].

Grant, A.M. (2001). Towards a psychology of coaching: The impact of Coaching on metacognition, mental health and goal attainment. Unpublished doctoral dissertation, Macquarie University, Sydney, New South Wales, Australia.

Grant, A.M. (2003a). Keeping up with the cheese! Research as a foundation for professional coaching of the future. Keynote Presentation of the International Coach Federation Conference Symposium on Research and Coaching, November, 2003, Denver, Colorado, USA.

Grant, A.M. (2003b). The impact of life coaching on goal attainment, metacognition and mental health. Social Behavior and Personality, 31(3), 253-264.

Habermas, J. (1978). Knowledge and human interest. London: Heinemann Educational.

Hargrove, R. (1995). Masterful Coaching: Extraordinary results by impacting people an the way they think and work together. San Francisco, Jossey-Bass Publishers.

Hargrove, R. (2003). Masterful Coaching (Revised Edition). San Francisco: Jossey-Bass Pfeiffer.

Hogan, M. (2004). Executive coaching: An answer for school principals? The Practising Administrator, 32004, pp. 4-6.

Hudson, F.M. (1999). Handbook of Coaching: A comprehensive resource guide for managers, International Coach Federation (1998). Client Survey Results and Press Release. [Online]. Available at: http://www.coachfederation.org/pressroom/pr-clientsurvey.asp [21 $2{ }^{\text {st }}$ October 21 2004].

International Coach Federation (2004). Coaching Core Competencies. [Online]. Available at: http://www.coachfederation.org/credentialing/en/core.htm [21st October 2004].

Joy, K.L. (2001). The archetypes of coaching: Using organic inquiry to learn about successful professional personal coaching. Unpublished masters dissertation, California Institute of Integral Studies, San Francisco, California, USA.

Keenan, T.P. \& Braxton-Brown, G. (1991). Techniques: Coach, Consultant, Critic, Counselor: The

Multiple Roles of the Responsive Facilitator. Journal of Adult Education, 19(2), insert.

Killion, J. (2002). Soaring with their own life coach. Journal of Staff Development, 23(2), 19-22.

Kopf, J.M., \& Kreuze, J.G. (1991). Achieving performance excellence: training the trainer. Mid American Journal of Business, 6 (1), 23-26.

Lewin, K. (1951). Field theory in social science. New York: Harper.

Mezirow, J. (2000). Learning as transformation: Critical perspectives on a theory in progress.San Francisco, Jossey-Bass Publishers.

Moran, L. (2003). A case study of informal learning among production workers. Unpublished doctoral dissertation, Columbia University Teachers College, USA.

Olivero, G. Bane, K.D., \& Kopelman, R.E. (1997). Executive coaching as a transfer training tool: Effects on productivity in a public agency. Public Personal Management, 26(4), 461-469.

Paige, H. (2002). Examining the effectiveness of executive coaching on executives. International Education Journal, 3(2), 61-70.

Parsloe, E. (1992). Coaching, mentoring and assessing: A practical guide to developing competence. London: Kogan Page.

Parsloe, E., \& Wray, M. (2000). Coaching and mentoring: Practical methods to improve learning. London: Kogan Page.

Passman, R. (2000). Pressure Cooker: Experiences with student centered teaching and learning in highstakes assessment environments. Paper presented at the annual meeting of the southwest research association (Dallas, TX, Jan 27-29, 2000) ERIC Document Reproduction Service No. ED440146)

Quick, J.C., \& Macik-Frey, M. (2004). Behind the Mask: coaching through deep interpersonal communication. Consulting Psychology Journal: Practice and Research, 56(2), 67-74.

Results Coaching Systems. (2004). The history of coaching. [Online]. Available at: www.workplacecoaching.com/resources.html [5 $5^{\text {th }}$ October 2004].

Whitmore, J. (2002). Coaching for performance. ( $\left.3^{\text {rd }} \mathrm{ed}.\right)$. London: Nicholas Brealey Publishing.

Whitworth, L., Kimsey-House, H., \& Sandahl, P. (1998). Co-Active Coaching. California: Davies Blade Publishing. 
